\title{
SYNTHESIS, CRYSTAL STRUCTURE, PHOTOLUMINESCENCE AND SEMICONDUCTIVE PROPERTIES OF A NOVEL TERBIUM COMPLEX
}

\author{
Xiao-Niu FANG, ${ }^{*}$ Xiu-Guang YI, Bo-Xiao TANG, Ren-Yun KUANG, Ya-Ping XU \\ School of Chemistry and Chemical Engineering, Institute of Applied Chemistry, \\ Jinggangshan University, Ji'an, Jiangxi, P.R. China, 343009
}

A new terbium complex, $\left[\mathrm{Tb}_{2}(\text { phenoxyacetic acid })_{6}\left(\mathrm{H}_{2} \mathrm{O}\right)_{3}\right]_{n} \bullet \mathrm{nH}_{2} \mathrm{O}$ (1) with a two-dimensional (2D) layered structure, has been prepared via a hydrothermal reaction and structurally characterized by single-crystal X-ray diffraction technique. Compound 1 crystallizes in the space group $P \overline{1}$ of the triclinic system with two formula units in one cell. Each terbium ion in compound $\mathbf{1}$ is coordinated by nine oxygen atoms to yield a monocapped tetragonal antiprism geometry. Photoluminescence spectra measured with solid-state sample of compound $\mathbf{1}$ demonstrate that the emission bands at 491, 545, 588 and $620 \mathrm{~nm}$ are observed from the $4 f$ intrashell transitions of the $\mathrm{Tb}^{3+}$ ions. These bands are originated from the ${ }^{5} \mathrm{D}_{4}$ excited state to the ${ }^{7} \mathrm{~F}_{6},{ }^{7} \mathrm{~F}_{5},{ }^{7} \mathrm{~F}_{4}$ and ${ }^{7} \mathrm{~F}_{3}$ states, respectively. Solid-state diffuse reflectance spectrum reveals the existence of a wide optical band

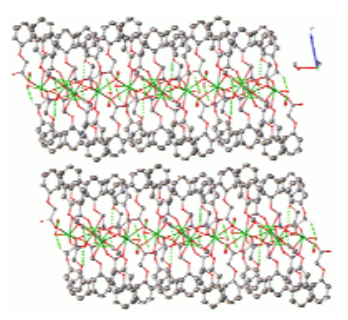
gap of $4.24 \mathrm{eV}$ of compound $\mathbf{1}$.

\section{INTRODUCTION}

In comparison with the transition metal ions, lanthanide ions have much higher coordination numbers that afford them more possibility to build new coordination structures. ${ }^{1-5}$ Lanthanide coordination polymers obtain ongoing interest due to their interesting structures and rich properties such as photoluminescent, semiconductive, catalytic and magnetic properties. ${ }^{6-8}$ These properties are, to our knowledge, originated from the unique $4 f$ electronic structures of the lanthanide ions. Based on these properties, lanthanide coordination compounds can be potentially applied in the areas of magnetic materials, light-emitting materials, electroluminescent devices, fluorescent probes, cell imaging, and so forth. ${ }^{9-11}$ A great deal of lanthanide coordination compounds have thus far been synthesized. With regard to lanthanide coordination compounds, they can generally display interesting photoluminescence if the $f-f$ electronic transition can happen. But actually lanthanide ions generally possess low absorption coefficient which blocks the $f-f$ electronic transition, leading to weak or even no emission. Organic ligands like aromatic carboxylic acids are capable of increasing the absorption coefficient of the lanthanide ions and, therefore, they are often used to design lanthanide photoluminescence compounds. This is because the organic ligands are able to absorb ultraviolet light and transfer the light energy to the lanthanide ions effectively, i.e. antenna effect. ${ }^{12-14}$ We recently become interested in the crystal engineering of lanthanide coordination compounds with novel structures and interesting properties. We report in this work the hydrothermal synthesis, singlecrystal X-ray structure, photoluminescent and semiconductive properties of a novel terbium coordination compound, $\left[\mathrm{Tb}_{2}\right.$ (phenoxyacetic acid $\left.)_{6}\left(\mathrm{H}_{2} \mathrm{O}\right)_{3}\right]_{\mathrm{n}} \cdot \mathrm{nH}_{2} \mathrm{O}(\mathbf{1})$, which is characteristic of a two-dimensional (2D) layered structure.

\footnotetext{
* Corresponding author: fangxiaoniu@163.com
} 


\section{RESULTS AND DISCUSSION}

Single-crystal X-ray diffraction results discover that compound $\mathbf{1}$ is comprised of electronic neutral 2D $\left.\left[\mathrm{Tb}_{2} \text { (phenoxyacetic acid }\right)_{6}\left(\mathrm{H}_{2} \mathrm{O}\right)_{3}\right]_{n}$ layers and lattice water molecules, as presented in Figure 1.

Compound $\mathbf{1}$ is crystallized in the space group $P \overline{1}$ of the triclinic system with two formula units in one cell. The terbium ions in compound $\mathbf{1}$ are all nine-coordinated to yield a monocapped tetragonal antiprism geometry, and which can be divided into two groups. The first group labelled with $\mathrm{Tb} 2$ is coordinated with one coordinating water and eight oxygen atoms from six phenoxyacetic acid ligands, in which two ligands connected as a bidentate chelating manner and the other four ligands coordinated to the terbium ion in a monooxygen manner. The second group labelled with Tb1 is coordinated with two coordinating water and seven oxygen atoms from five phenoxyacetic acid ligands, in which one ligands connected as a bidentate chelating manner and the other five ligands coordinated to the terbium ion in a monooxygen manner. The bond lengths of $\mathrm{Tb}$ $\mathrm{O}_{\text {phenoxyacetic acid }}$ are in a wide range of $2.276(2) \AA-$ 2.511(2) $\AA$ with an average value of 2.400(2) $\AA$ which is normal and comparable with those found in the references. ${ }^{15-17}$ The bond lengths of $\mathrm{Tb}-\mathrm{O}_{\text {water }}$ are in the range of 2.378 (2) $\AA-2.452(2) \AA$. The result of the bond valence calculation reveals that all of the terbium ions are in $\mathrm{a}+3$ oxidation state ( $\mathrm{Tb}(1): 3.214 ; \mathrm{Tb}(2): 3.150) .{ }^{18}$ In the title complex, all of the phenoxyacetic acid moieties act as bridging ligands. The phenoxyacetic acid moieties are divided into two groups. One takes the 2.11 mode, labelled by Harris notation, ${ }^{19}$ linking to two terbium ions with each carboxyl oxygen atom coordinating to one terbium ion. The other takes the 2.21 mode, links to two terbium ions with one carboxyl oxygen atom coordinating to two terbium ions, while the other carboxyl oxygen atom only coordinates to one terbium ion. Every two terbium ions interconnect together via three phenoxyacetic acid ligands to give a $1 \mathrm{D}$ chain running along the $b$ direction. These chains further interconnect together via the phenoxyacetic acid ligands to yield a $2 \mathrm{D}$ layer running parallel to the $a b$ plane, as shown in Figure 2.

The $\mathrm{Tb} \cdots \mathrm{Tb}$ distances are in the range of 4.3112(7) $\AA-4.5246(7) \AA$ 。 In compound 1, there are several $\mathrm{O}-\mathrm{H} \cdots \mathrm{O}$ and $\mathrm{C}-\mathrm{H} \cdots \mathrm{O}$ hydrogen-bonding interactions. The layers stack together via Van der Waals interaction to build a crystal packing structure, as presented in Figure 3.

To our knowledge, terbium compounds can generally display excellent photoluminescence and, up to date, a great number of terbium compounds with interesting photoluminescent properties have been documented. ${ }^{20-23}$ Therefore, for the sake of revealing the potential photoluminescent behavior, we carried out the photoluminescent experiments for compound $\mathbf{1}$ with solid state sample under room temperature. The measurement results of the photoluminescence experiments are depicted in Figure 4.

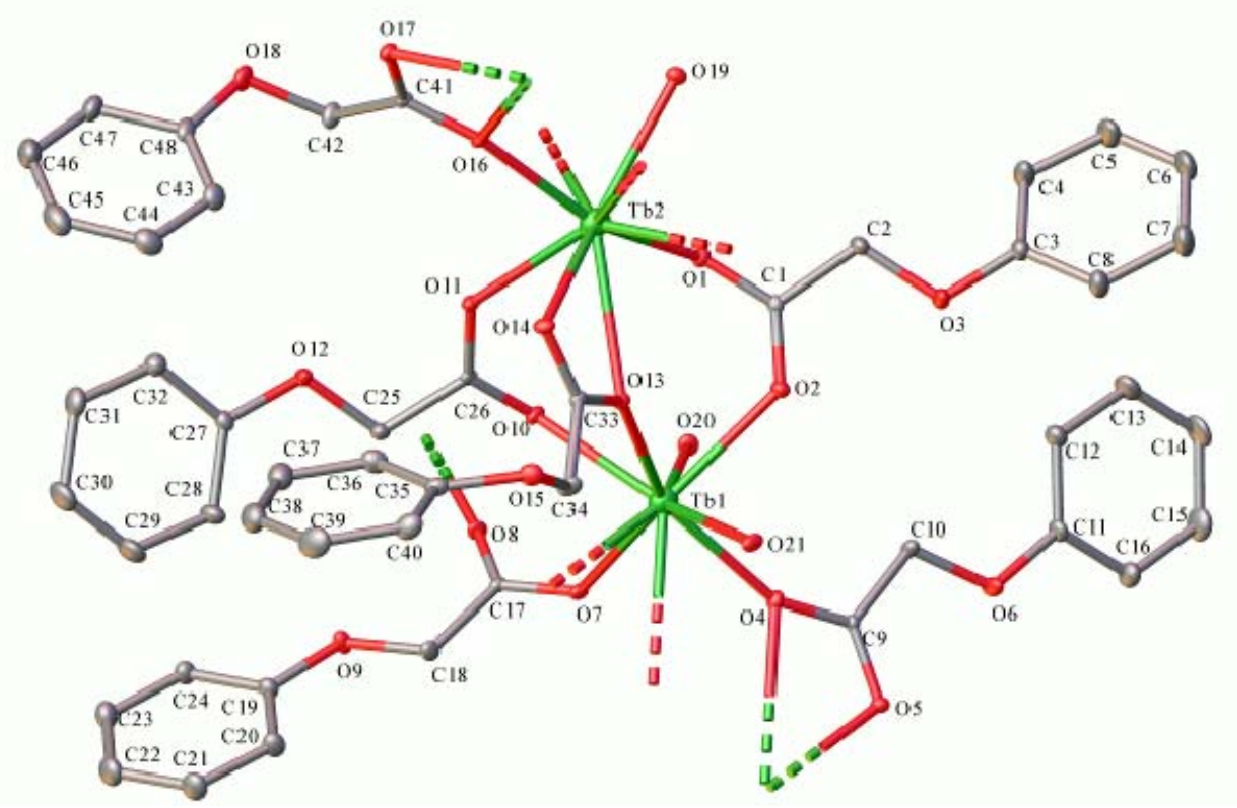

Fig. 1 - The asymmetric unit structure of 1 with small sphere atom type. Lattice water molecules and hydrogen atoms have been omitted for clarity. 


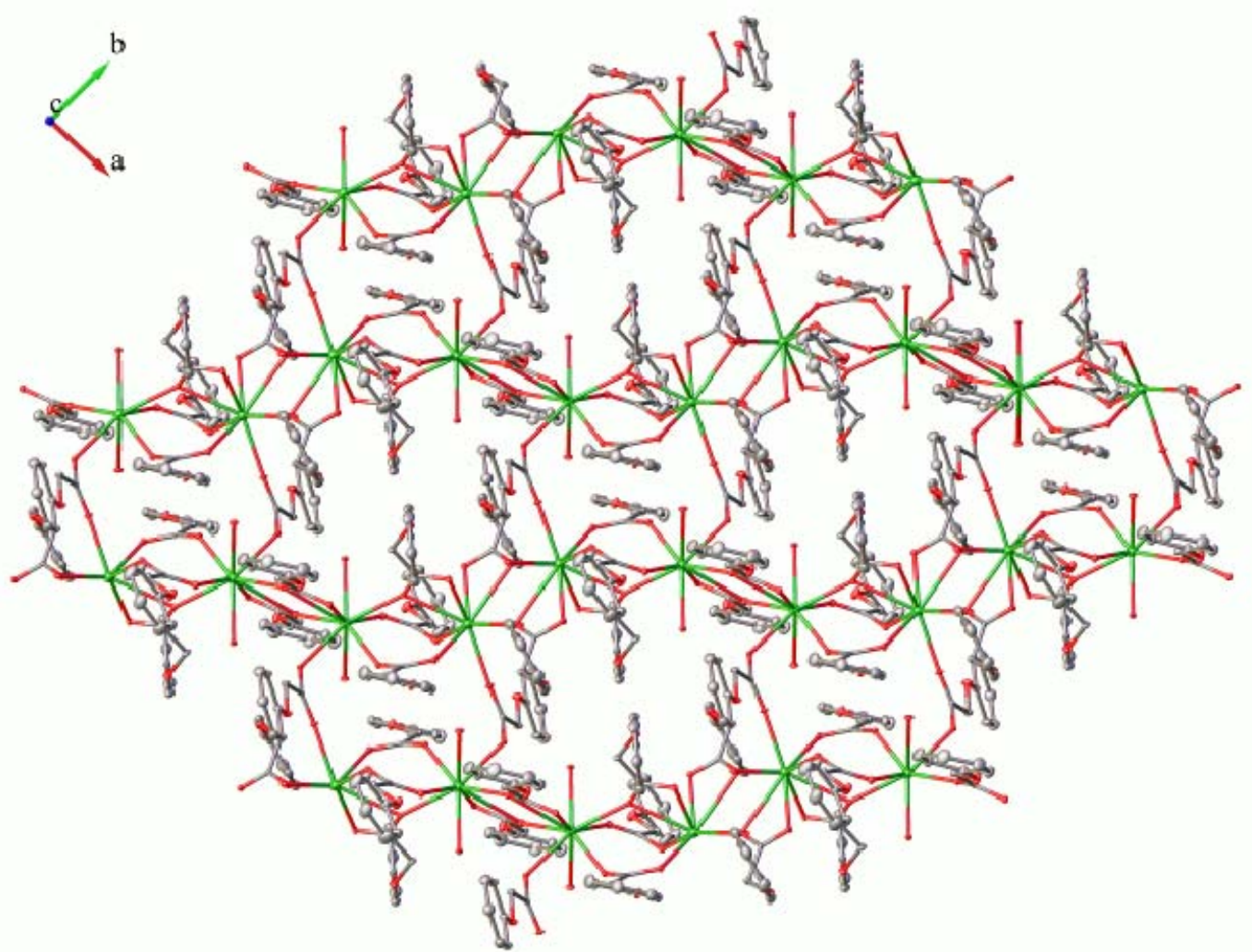

Fig. 2 - The 2D layer viewed down from the $c$-axis. Lattice water molecules and hydrogen atoms have been omitted for clarity.

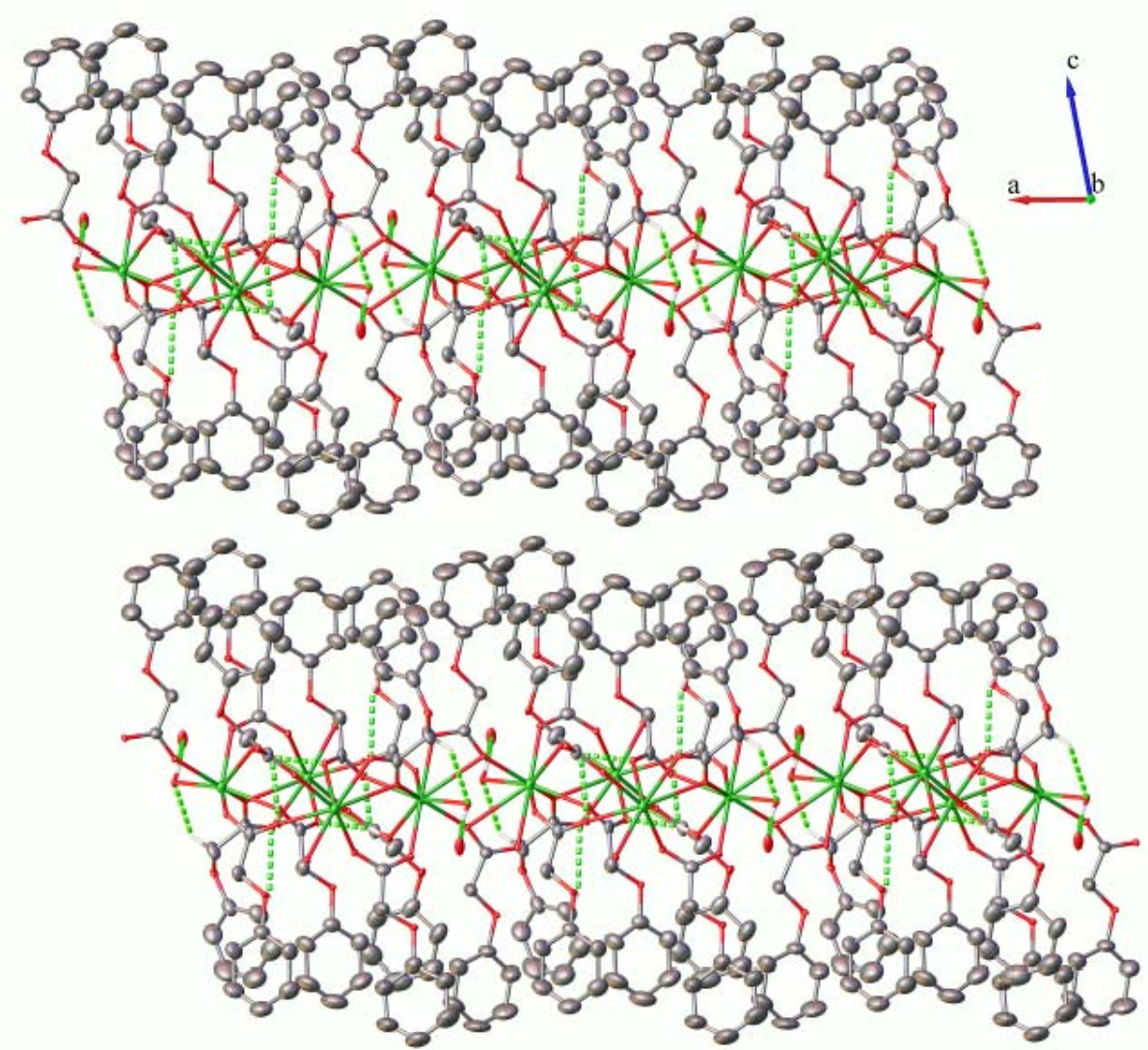

Fig. 3 - A packing diagram of 1 with the dashed lines representing the hydrogen bonding interactions $\left(\AA,{ }^{\circ}\right): \mathrm{O} 21-\mathrm{H} 21 \mathrm{~A} \cdots \mathrm{O} 22$,

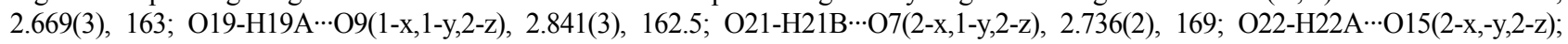
C34-H34A $\cdots \mathrm{O} 5(2-\mathrm{x}, 1-\mathrm{y}, 2-\mathrm{z}), 3.058(3), 131$. 


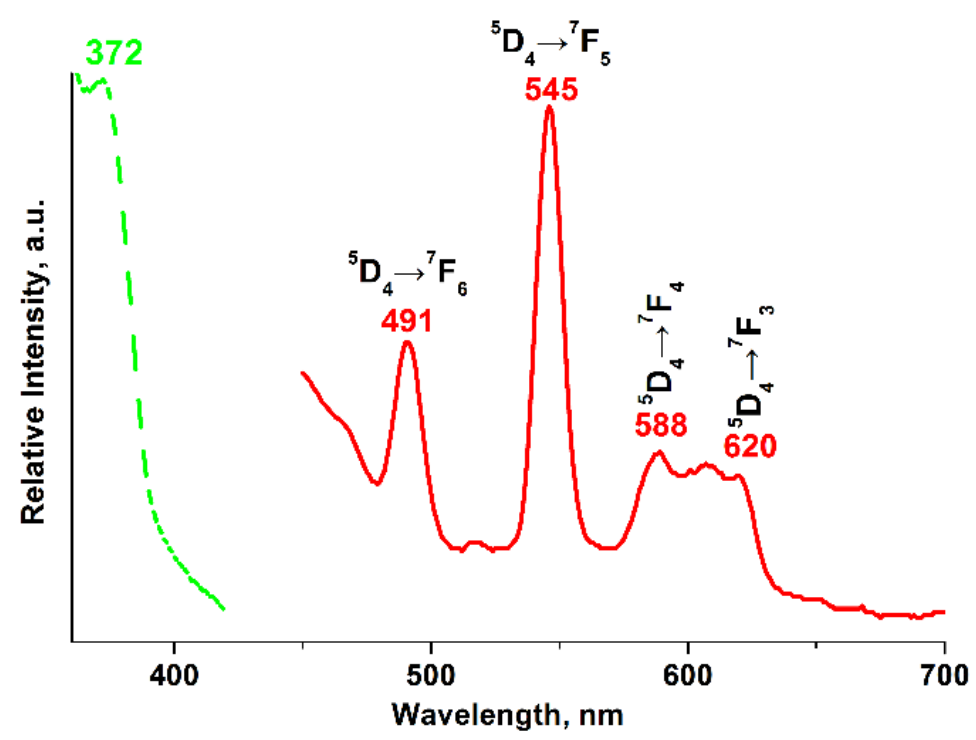

Fig. 4 - Solid-state photoluminescent spectra of 1 measured at room temperature. Green: excitation; red: emission.

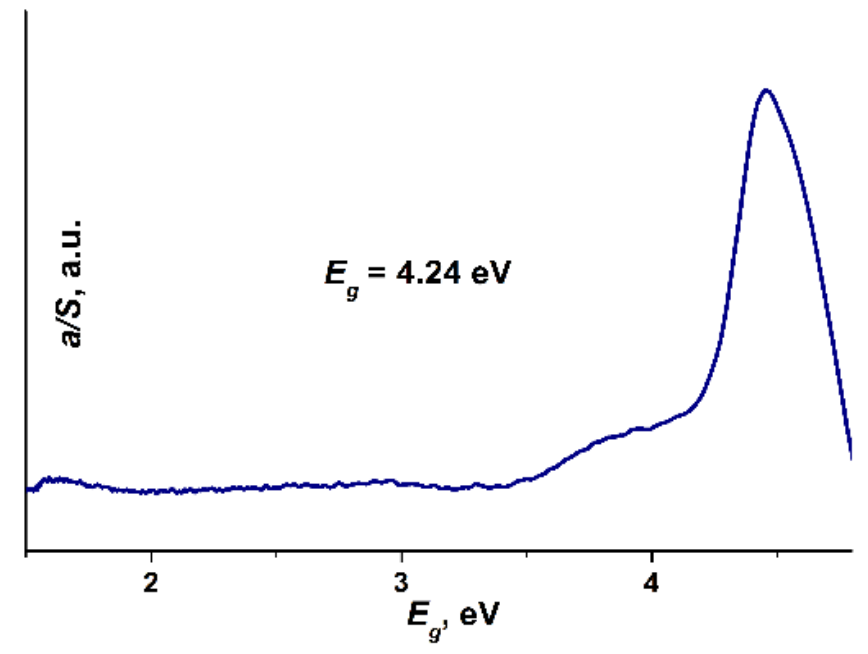

Fig. 5 - Solid-state diffuse reflectance spectrum for 1.

It is clearly that the photoluminescence spectrum of compound 1 shows an effective energy absorption mainly locating in the wavelength span of 360$390 \mathrm{~nm}$. Upon the green light emission of $545 \mathrm{~nm}$, the excitation spectrum displays a peak at $372 \mathrm{~nm}$. Then, we further carried out the corresponding photoluminescence emission spectrum of compound 1. It was found that when it was excited by using the wavelength of $372 \mathrm{~nm}$, the emission peaks at 491, 545,588 and $620 \mathrm{~nm}$ are observed from the $4 f$ intrashell transitions of the $\mathrm{Tb}^{3+}$ ions. These peaks are determined to be originated from the ${ }^{5} \mathrm{D}_{4}$ excited state to the ${ }^{7} \mathrm{~F}_{6},{ }^{7} \mathrm{~F}_{5},{ }^{7} \mathrm{~F}_{4}$ and ${ }^{7} \mathrm{~F}_{3}$ states, respectively. This suggests that effective energy transfer has happened and a conjugated system has formed between the phenoxyacetic acid and the chelated $\mathrm{Tb}^{3+}$ ion. As a result, phenoxyacetic acid is a suitable antenna for the photoluminescence of 1 and compound $\mathbf{1}$ is possibly a potential green light photoluminescence material.

Solid-state UV/vis diffuse reflectance experiment of compound $\mathbf{1}$ was performed by using powder sample under room temperature. The data obtained from the solid-state diffuse reflectance spectrum were treated by virtue of the Kubelka-Munk function (i.e. $\alpha / S=(1-R)^{2} / 2 R$ ) of which the $\alpha$ is the absorption coefficient, $S$ means the scattering coefficient and $R$ refers to the reflectance. By extrapolating from the linear part of the main absorption edge of the $\alpha / S$ vs. energy diagram, we determined the optical band gap value of compound 1. The solid-state $\mathrm{UV} / \mathrm{vis}$ diffuse reflectance experiment uncovers that compound 1 exhibits a wide optical band gap of $4.24 \mathrm{eV}$, as depicted in Figure 5. 
As a result, compound $\mathbf{1}$ is possibly a candidate for wide band gap semiconductive materials. The steep slope of the optical absorption edge suggests that compound 1 might has a direct transition. ${ }^{24}$ The optical band gap of $4.24 \mathrm{eV}$ of compound $\mathbf{1}$ is smaller than that of diamond $(5.47 \mathrm{eV})$ which is one of the third generation semiconductive materials, ${ }^{25}$ but it is clearly larger than that of GaAs $(1.4 \mathrm{eV})$, CdTe $(1.5 \mathrm{eV})$ and $\mathrm{CuInS}_{2}(1.55$ $\mathrm{eV})$ which are well-known as highly efficient narrow band gap photovoltaic materials. ${ }^{26}$

\section{EXPERIMENTAL}

Preparation and characterization of $\left.\left[\mathrm{Tb}_{2} \text { (phenoxyacetic acid }\right)_{6}\left(\mathrm{H}_{2} \mathrm{O}\right)_{3}\right]_{\mathbf{n}} \bullet \mathrm{nH}_{2} \mathrm{O}(1)$

All the chemicals and reagents are of analytical grade, commercially available and applied without further purification. Compound $\mathbf{1}$ was synthesized by mixing $\mathrm{TbCl}_{3} \cdot 6 \mathrm{H}_{2} \mathrm{O}(1 \mathrm{mmol}, 374 \mathrm{mg})$, phenoxyacetic acid $(3 \mathrm{mmol}$, $456 \mathrm{mg}$ ) and distilled water $(10 \mathrm{~mL})$ into a $25 \mathrm{~mL}$ Teflon-lined stainless steel container, heated at $453 \mathrm{~K}$ in an oven for 7 days and then power off. Once the container was cooled to room temperature, colorless block-like crystals were collected and applied for single-crystal X-ray data collection. The yield was $51 \%$ based on terbium. Photoluminescence measurement was performed on the F97XP photoluminescence spectrometer.
Solid-state UV/vis spectrum with powder sample was conducted under room temperature on a computer-controlled TU1901 UV/vis spectrometer attached with an integrating sphere and $\mathrm{BaSO}_{4}$ powder was applied as a $100 \%$ reflectance reference.

\section{X-ray crystallographic investigation}

The diffraction data was measured on a Rigaku mercury CCD X-ray diffractometer with a selected single-crystal of the compound $\mathbf{1}$. The X-ray source is graphite monochromated Mo$K \alpha$ radiation with the $\lambda$ being of $0.71073 \AA$. The diffraction data reduction and empirical absorption correction were performed by using the CrystalClear software. ${ }^{27}$ The single-crystal structure was solved by means of the direct method and the Olex 2 software, ${ }^{28}$ as well as refined with a full-matrix least-squares refinement on $F^{2}$. All non-hydrogen atoms were found based on the difference Fourier maps and anisotropically refinement, while the nonwater hydrogen atoms were theoretically generated, attached to the parent atoms and involved in the structural factor calculation using assigned isotropic thermal parameters. Positional parameters of the $\mathrm{H}$ atoms of the water molecules were obtained from difference Fourier syntheses and verified according to the geometrical parameters of the H-bonds. The crystal data of the collection and refinement are depicted in Table 1 . Crystallographic data for the structural analysis have been deposited with the Cambridge Crystallographic Data Centre, CCDC No. 1581367. Copies of this information may be obtained free of charge from the Director, CCDC, 12 Union Road, Cambridge, CBZ 1EZ, UK (Fax: +44-1223-336033; email: deposit@ccdc.cam.ac.uk or http://www.ccdc. cam.ac.uk).

Table 1

Important crystallographic data of compound $\mathbf{1}$

\begin{tabular}{|c|c|}
\hline Formula & $\mathrm{C}_{48} \mathrm{H}_{50} \mathrm{O}_{22} \mathrm{~Tb}_{2}$ \\
\hline Formula weight & 1296.72 \\
\hline color & colorless \\
\hline Crystal size $/ \mathrm{mm}^{3}$ & 0.160 .110 .09 \\
\hline Crystal system & triclinic \\
\hline Space group & $P \overline{1}$ \\
\hline$a(\AA)$ & $11.431(2)$ \\
\hline$b(\AA)$ & $11.567(2)$ \\
\hline$c(\AA)$ & $19.436(3)$ \\
\hline$\alpha\left({ }^{\circ}\right)$ & $85.051(6)$ \\
\hline$\beta\left(\left(^{\circ}\right)\right.$ & $79.390(5)$ \\
\hline$\gamma\left({ }^{\circ}\right)$ & $86.591(6)$ \\
\hline$V\left(\AA^{3}\right)$ & $2513.9(7)$ \\
\hline$Z$ & 2 \\
\hline $2 \theta_{\max }\left({ }^{\circ}\right)$ & $6.42 \sim 50$ \\
\hline \multirow[t]{3}{*}{ 3. Index ranges } & $-14 \leq h \leq 14$ \\
\hline & $-12 \leq k \leq 15$ \\
\hline & $-25 \leq l \leq 23$ \\
\hline Reflections collected & 17869 \\
\hline Independent, observed reflections $\left(R_{\text {int }}\right)$ & $8293,6639(0.0516)$ \\
\hline$d_{\text {calcd. }}\left(\mathrm{g} / \mathrm{cm}^{3}\right)$ & 1.713 \\
\hline$\mu\left(\mathrm{mm}^{-1}\right)$ & 2.872 \\
\hline$T(\mathrm{~K})$ & $293(2)$ \\
\hline$F(000)$ & 1288 \\
\hline$R 1, w R 2$ & $0.0307,0.0706$ \\
\hline$S$ & 0.922 \\
\hline Largest and Mean $\Delta / \sigma$ & $0.002,0$ \\
\hline$\Delta \rho(\max , \min )\left(\mathrm{e} / \AA^{3}\right)$ & $1.51,-1.34$ \\
\hline
\end{tabular}




\section{CONCLUSIONS}

In summary, a novel terbium complex with a $2 \mathrm{D}$ layered structure has been prepared via a hydrothermal reaction and structurally characterized by single-crystal X-ray diffraction technique. Each terbium ion is coordinated by nine oxygen atoms to form a monocapped tetragonal antiprism geometry. It exhibits the photoluminescence emission bands at 491, 545, 588 and $620 \mathrm{~nm}$ which are originated from the $4 f$ intrashell transitions of the ${ }^{5} \mathrm{D}_{4}$ excited state to the ${ }^{7} \mathrm{~F}_{6},{ }^{7} \mathrm{~F}_{5},{ }^{7} \mathrm{~F}_{4}$ and ${ }^{7} \mathrm{~F}_{3}$ states of the $\mathrm{Tb}^{3+}$ ions, respectively. Solid-state diffuse reflectance spectrum reveals the existence of a wide optical band gap of $4.24 \mathrm{eV}$. Therefore, it is possibly a candidate for green light photoluminescence materials or wide band gap semiconductive materials.

Acknowledgements. The authors gratefully acknowledged the financial support by the National Natural Science Foundation of China (NSFC 51363009).

\section{REFERENCES}

1. D. Yoshioka, Y. Nishimura, K-I. Katsumata, J. Lumin., 2018, 194, 316-320.

2. K. Wang, Y. Ma, H.Tang, Cryst., 2017, 7, 199-209

3. X. Zhou, L.Chen, Z. Feng, S. Jiang, J. Lin, Y. Pang, L. Li, Xiang G. Inorg. Chim. Acta, 2018, 469, 576-582.

4. P. Mukherjee, Y. Wu, G.I. Lampronti, S. E. Dutton, Mater. Res. Bull., 2018, 98, 173-179.

5. F. Gao, Y. Li, Y. Ye, Zhao L., Inorg. Chem. Commun., 2017, 86, 137-139.

6. B. Gao, Z. Jiang, M. Zhao, H. Wu, F. Pan, J.Q. Mayta, Z. Chang, X. Bu, J. Membr. Sci., 2018, 546, 31-40.

7. Z. Du, J. Sun, C. A. Bader, D. A. Brooks, M. Li, X. Li, S E. Plush, J. Inorg. Biochem., 2018, 178, 32-42.

8. N. S. Kariaka, V. A. Trush, S. S. Smola, Y. M. Fadieiev, V. V. Dyakonenko, S. V. Shishkina, T. Y. Sliva, V. M. Amirkhanov, J. Lumin., 2018, 194, 108-115.
9. T. C. Monson, T. E. Stevens, J. L. Leger, J. L. Manson, K. S. Lovejoy, A. L. Newsham, R. E. Del Sesto, Chem. Commun. (Cambridge, U. K.), 2017, 53, 11682-11685.

10. T. P. Latendresse, N. S. Bhuvanesh, M. Nippe, J. Am. Chem. Soc., 2017, 139, 14877-14880.

11. S.-Y. Lin, J. Wu, Z. Xu, RSC Adv., 2017, 7, 4752047526.

12. A. Picot, F. Malvolti, B. Le Guennic, P. L. Baldeck, J.A.G. Williams, C. Andraud, O. Maury, Inorg. Chem., 2007, 46, 2659-2665.

13. L. Shen, M. Shi, F. Li, D. Zhang, X. Li, E. Shi, T. Yi, Y. Du, C. Huang, Inorg. Chem., 2006, 45, 6188-6197.

14. A. P. S. Samuel, E. G. Moore, M. Melchior, J. Xu, K. N. Raymond, Inorg. Chem., 2008, 47, 7535-7544.

15. N. Goel, N. Kumar, Inorg. Chim. Acta, 2017, 463, 14-19.

16. G. Novitchi, S. Shova, J. P. Costes, O. Mamula, M. Gdaniec, Inorg. Chim. Acta, 2005, 358, 4437-4442.

17. O. M. A. Guino, B. Bustrom, R. A. Tigaa, A. De Bettencourt-Dias, Inorg. Chim. Acta, 2017, 464, 23-30.

18. I. D. Brown, D. Altermatt, Acta Crystallogr., Sect. B: Struct. Sci., 1985, B41, 244-247.

19. R. A. Coxall, S. G. Harris, D. K. Henderson, S. Parsons, P. A. Tasker, R. E. P. Winpenny, J. Chem. Soc., Dalton Trans., 2000, 14, 2349-2356.

20. K. Ueda, Y. Shimizu, K. Nagamizu, M. Matsuo, T. Honma, Inorg. Chem., 2017, 56, 12625-12630.

21. V. Uma, M. Vijayakumar, K. Marimuthu, G. Muralidharan, J. Mol. Struct., 2018, 1151, 266-276.

22. S. Zhang, Z. Mu, Y. Lv, L. Fan, Y. Li, G. Ju, Y. Hu, J. Alloys Compd., 2017, 729, 418-425.

23. X. Li, X. Chen, S. Yuan, S. Liu, C. Wang, D. Chen, J. Mater. Chem. C, 2017, 5, 10201-10210.

24. F. Q. Huang, K. Mitchell, J.A. Iber, Inorg. Chem., 2001, 40, 5123-5126.

25. C. Rumpf, R. Tillinski, C. Nather, P. Durichen, I. Jess, W. Bensch, Eur. J. Solid State Inorg. Chem., 1997, 34, 1187-1198.

26. R. Tillinski, C. Rumpf, C. Naether, P. Duerichen, I. Jess, S.A. Schunk, W.Z. Bensch, Anorg. Allg. Chem., 1998, 624, 1285-1290.

27. Rigaku, CrystalClear Version 1.35, Rigaku Corporation, 2002.

28. O.V. Dolomanov, A. J. Blake, N.R. Champness, M. Schröder, J. Appl. Crystallogr., 2003, 36, 1283-1284. 